\title{
Essais
}

Revue interdisciplinaire d'Humanités

$10 \mid 2016$

Faire-valoir et seconds couteaux

\section{De « Sidekicks and Underlings » à « Faire-valoir et seconds couteaux $»$ : remarques sémantiques}

Avant-propos

Jean-Paul Gabilliet

\section{OpenEdition}

\section{Journals}

Édition électronique

URL : http://journals.openedition.org/essais/3722

DOI : 10.4000/essais.3722

ISSN : 2276-0970

Éditeur

École doctorale Montaigne Humanités

Édition imprimée

Date de publication : 15 septembre 2016

Pagination : 15-17

ISBN : 978-2-9544269-9-0

ISSN : $2417-4211$

Référence électronique

Jean-Paul Gabilliet, « De « Sidekicks and Underlings » à « Faire-valoir et seconds couteaux »:

remarques sémantiques », Essais [En ligne], 10 | 2016, mis en ligne le 15 octobre 2020, consulté le 21

octobre 2020. URL : http://journals.openedition.org/essais/3722 ; DOI : https://doi.org/10.4000/

essais.3722 


\section{De « Sidekicks and Underlings » à "Faire-valoir et seconds couteaux ": remarques sémantiques}

\section{Avant-propos}

\section{Jean-Paul Gabilliet}

La thématique de ce numéro d'ESSAIS, «Faire-valoir et seconds couteaux ", est la " traduction » française de l'intitulé du colloque organisé en octobre 2014 à l'Université Bordeaux Montaigne par l'équipe CLIMAS, "Sidekicks and Underlings ".

Formulé initialement en anglais, le titre de la manifestation a posé un certain nombre de problèmes quand est venu le moment d'en proposer une traduction. Si sidekicks et underlings sont pour des locuteurs anglophones des termes relativement univoques, leur transposition n'est pas une tâche facile dans la mesure où ces deux substantifs s'inscrivent chacun dans un champ sémantique qui s'ajuste imparfaitement à des équivalents français.

Sidekick émerge d'une inextricable brume étymologique au début du $\mathrm{XX}^{\mathrm{e}}$ siècle en anglais américain. La page Wikipedia qui y est consacrée retient une origine issue de l'argot des pickpockets selon laquelle le terme renvoyait à la poche de devant dans un manteau ou un pantalon (par opposition à la poche arrière, qualifiée en anglais de "poche de hanche ", hip pocket) ; cette poche étant la plus difficile d'accès pour un pickpocket, elle était assimilée au meilleur ami de la victime potentielle. ${ }^{1}$ Dans son dictionnaire d'argot américain, Robert L. Chapman propose deux autres origines : une dérivation de sidekicker, lui-même issu de kicker, qui désigne la carte finale donnant la victoire dans une partie de cartes; ou une allusion au comparse qui, dans un combat, donne des coups de pied (kick) par le côté (side) là où le combattant principal les donne par devant. ${ }^{2} \mathrm{Si}$ on se souvient, par ailleurs, que kick désigne en menuiserie une pièce de bois qui en soutient une autre, s'ouvre une nouvelle piste qui embrouille davantage la recherche.

Devant le caractère labyrinthique de la piste étymologique, il est préférable de se rabattre sur la piste sémantique : tous les dictionnaires de la langue anglaise s'entendent à définir sidekick comme un compagnon qui est parte-

1 https://en.wikipedia.org/wiki/Sidekick (consulté le 18 août 2015).

2 Robert L. Chapman (ed.), American Slang (New York: Harper \& Row, 1987), 399 p. 
naire et/ou subordonné. C'est de cette ambiguïté que procède le problème de traduction en français : acolyte, assistant, associé, auxiliaire, comparse, compère, complice... - tous ces noms gravitent autour de sidekick sans le transposer de manière satisfaisante. Aucun d'eux n'est porteur de l'exacte ambivalence sémantique (partenaire etlou subordonné) qui confère au substantif anglais la valeur notionnelle large permettant de faire entrer dans une même rubrique le Sancho Panza de Don Quichotte, le Catalinon (Sganarelle, Leporello, etc.) de Don Juan, le Watson de Sherlock Holmes, le Robin de Batman, le Bérurier de San-Antonio, etc.

Simultanément, tous relèvent en français de la catégorie générale du faire-valoir, personnage de rang deux dont la fonction est de faire ressortir les caractéristiques profondes, aussi bien positives que négatives, du personnage de rang un. On pourra objecter à bon droit que " faire-valoir " a un équivalent anglais : foil, issu du vieux français fueille (qui a donné feuille), qualifie à partir du XIV ${ }^{e}$ siècle une fine feuille de métal puis, à partir du XVI siècle, les feuilles métalliques sur lesquelles sont présentées les pierres précieuses pour faire ressortir leur éclat.

Au bout du compte, sidekicks et faire-valoir renvoient bien aux mêmes personnages. Ils repèrent le héros au moyen d'une détermination spatiale : le sidekick, qui se situe par définition sur le côté, contribue à construire l'espace central occupé par le protagoniste, de la même façon que le faire-valoir qui, si l'on suit la racine étymologique de foil, se situe en arrière du protagoniste (auquel la position en avant confere sa centralité). Comme quoi la dialectique centre-périphérie est une stratégie fort ancienne et infiniment répandue de mise en scène des personnages au sein de toutes les espèces narratives.

Et underling dans tout ça ? À l'inverse de sidekick, c'est un terme dont l'histoire est clairement attestée : apparu au XII ${ }^{\mathrm{e}}$ siècle, il désigne en moyen anglais un valet, laquais, etc. En anglais contemporain, le terme a pris la connotation négative d'un inférieur hiérarchique au libre arbitre limité, prêt à exécuter tous les ordres qui lui sont donnés; son synonyme le plus proche est minion, terme récemment remis à la mode par des personnages de dessin animé à succès. D'où la traduction finalement choisie, "second couteau " : tant pour le Dictionnaire de l'Académie française que pour le Petit Larousse illustré, l'expression renvoie aux seconds rôles du théâtre (alors que l'anglais, pour l'image équivalente, emprunte sa métaphore au domaine musical en parlant de second fiddle, "deuxième violon ") et, par extension, désigne un comparse. Dans l'usage français, l'expression véhicule clairement une idée d'infériorité dans un ordre ou une hiérarchie, connotation absente a priori de « faire-valoir». 
Au final, " faire-valoir et seconds couteaux ", tout comme « sidekicks and underlings ", couvre un large spectre de seconds rôles : de ceux qui contribuent directement à la construction des protagonistes jusqu'aux hallebardiers qui traversent le scène ou aux "porte-flingues " qui décèdent par cohortes dans les films d'action!

Jean-Paul Gabilliet

EA 4196 CLIMAS

Université Bordeaux Montaigne

Jean-Paul.Gabilliet@u-bordeaux-montaigne.fr 